\title{
Effect of iodothyronine hormone status on doxorubicin related cardiotoxicity
}

\author{
J. Dudka ${ }^{1}$, S. Mandziuk², B. Madej-Czerwonka3 ${ }^{3}$ J. Sierocińska-Sawa4 ${ }^{4}$ B. Walczyna4,
} A. Korga' ${ }^{1}$, M. Cendrowska-Pinkosz ${ }^{3}$, F. Burdan ${ }^{3,5}$

\author{
${ }^{1}$ Medical Biology Unit, Medical University of Lublin, Lublin, Poland \\ ${ }^{2}$ Department of Pneumology Oncology and Alergology, Medical University of Lublin, Lublin, Poland \\ ${ }^{3}$ Department of Human Anatomy, Medical University of Lublin, Lublin, Poland \\ ${ }^{4}$ Department of Clinical Pathomorphology, Medical University of Lublin, Lublin, Poland \\ ${ }^{5}$ St. John's Cancer Centre, Lublin, Poland
}

[Received 20 May 2013; Accepted 7 June 2013]

\begin{abstract}
The anthracycline anticancer agent doxorubicin has been recognised to induce a dose-dependent cardiotoxicity. The chronic form of such complication is characterised by an irreversible cardiac damage and congestive heart failure. Although the pathogenesis of anthracycline cardiotoxicity seems to be multifactorial, the pivotal role has been attributed to reactive oxygen species formation. Because redox equilibrium in cardiomyocytes may be regulated via iodothyronine hormones, the aim of the study was to appraise the effect of hypothyroidism on heart damages induced by doxorubicin. The rats received methimazole in drinking water 10.001 and $0.025 \%$ ) after doxorubicin administration (2.0, 5.0 and $15 \mathrm{mg} / \mathrm{kg}$ ). The cardiac morphology and blood biochemical markers of heart damage were assessed. Decreased levels of iodothyronine hormones had not significant impact on cardiac morphological changes and no effect on the level of B-type natriuretic peptide in rats receiving doxorubicin. Lower hormonal levels had sporadic, diverse effect on blood transaminases, lactate dehydrogenase and creatine kinase levels, but any relation to time, doxorubicin doses and hypothyroid status was found. Hypothyreosis leads to increase in fatty acid binding protein in rats receiving higher dose of doxorubicin. Hypothyreosis had no effect on heart stretching and on necrosis at morphological level, but caused biochemical symptoms of cardiomyocyte necrosis in rats receiving doxorubicin. (Folia Morphol 2013; 72, 4: 340-348)
\end{abstract}

Key words: doxorubicin, cardiotoxicity, hypothyreosis

\section{INTRODUCTION}

Doxorubicin is an effective antineoplastic drug used in various neoplasm diseases. The drug usefulness is limited by dose-dependent cardiotoxicity, which is secondary to generation of reactive oxygen species. Changes in redox equilibrium lead to oxidative damages of lipids, proteins and DNA [11, $13,21]$. The regulation of antioxidative defence is multifactorial. Many studies have indicated connections of iodothyronine hormones with oxidative stress
$[1,4,7,16,20]$. NADPH ${ }_{2}$ cytochrome $\mathrm{P}-450$ reductase $(P-450 R)$, the main enzyme responsible for the doxorubicin-dependent free radical generation, is strictly regulated by triiodothyronine $(\mathrm{T} 3)[8,17]$ and markedly decreased level of this enzyme (30-50\%) was observed in heart of rats treated with methimazole $[25,28]$. Moreover, malic enzymes, G6PDH and 6 PDGH, pivotal enzymes connected with glutathione reduction, are transcriptionally regulated by $\mathrm{T} 3[15$, 19]. The oxidative damages in the heart may result in 
morphological changes, e.g. necrosis, and releasing of cytoplasmatic proteins from cardiomyocytes to the blood. Thus, the aim of the study was the assessment of methimazole-induced hypothyreosis on cardiotoxicity induced by doxorubicin.

\section{METHODS}

\section{Animals and treatment}

The study was approved by the Local Ethical Committee at the Medical University of Lublin. Male Wistar rats (180-220 g) were kept under conventional laboratory conditions (temperature $22^{\circ} \mathrm{C}$, humidity 60-70\%, $12 \mathrm{~h}$ light/dark cycle) and fed with standard rodent granulated fodder LSM ${ }^{\circledR}$ (AGROPOL, Poland). Food and water were freely available. Animals were randomly divided into experimental and control groups (7 animal/group). Rats received thyreostatic drug - methimazole (methizole; ICN Polfa Rzeszów, Poland) in drinking water for 3 weeks at 2 concentrations $\left(0.001\right.$ or $0.025 \%$; group $\mathrm{MET}_{\mathrm{L}}$ or $\mathrm{MET}_{\mathrm{H}}$, respectively). For the remaining time of the experiment only filtrate municipal water was administered. $48 \mathrm{~h}$ after completing methimazole administration, the rats received doxorubicin (EBEWE Arzneimittel Ges.m.b.H., Austria) at the concentration of 2.0, 5.0 and $15 \mathrm{mg} /$ $/ \mathrm{kg}$ of the body weight (2DOX+MET $\mathrm{L}^{\prime} 5 \mathrm{DOX}+\mathrm{MET}_{\mathrm{L}^{\prime}}$ 15DOX $+\mathrm{MET}_{\mathrm{L}}$ and $2 \mathrm{DOX}+\mathrm{MET}_{\mathrm{H}^{\prime}}$ 5DOX $+\mathrm{MET}_{\mathrm{H}^{\prime}}$ $15 \mathrm{DOX}+\mathrm{MET}_{\mathrm{H}}$ groups). Doxorubicin hydrochloric was dissolved $(1: 1 ; \mathrm{v} / \mathrm{v})$ in a saline solution (Cefarm, Poland). The other groups were exposed exclusively to doxorubicin, but without inducing hypothyreosis (2DOX, 5DOX and 15DOX group). The biological materials (blood and hearts) were collected 4, 48 and $96 \mathrm{~h}$ after doxorubicin administration. In $\mathrm{MET}_{\mathrm{L}}$ and $\mathrm{MET}_{\mathrm{H}}$ groups, $48 \mathrm{~h}$ after cessation of methimazole, rats were administered with saline and after the next $96 \mathrm{~h}$ the biological material was collected for further biochemical analyses. A similar procedure was applied in control group, in which $96 \mathrm{~h}$ after the saline injection rats were scarificed.

The blood was aspirated from the left ventricle during the pentobarbital anaesthesia and the obtained plasma was storage at $-75^{\circ} \mathrm{C}$. Immediately afterwards, the thyroid gland and heart were removed during autopsy, washed with $20 \mathrm{~mL}$ of saline, and fixed in the buffered $10 \%$ formalin and routinely histologically processed to paraffin blocks. Slides were stained with hematoxilin and eosin $(\mathrm{H}+\mathrm{E})$ and evaluated, without the knowledge of the treated- -group, under light microscope (Olympus BX45; Tokyo, Japan).

\section{Determination of plasma biochemical parameters}

Triiodothyronine (FT3) and tetraiodothyronine (FT4) concentrations in rat plasma were measured using commercial reagents (AxSYM; Abbott, USA). The sample and antibody — coated microparticles added with reagent form an antibody-antigen complex. The T3 or T4 - alkaline phosphatase conjugate binds to the available site on the anti-T3 (anti-T4) coated microparticles. Finally, 4-methylumbeliferyl phosphate was added and the fluorescent intensiveness of the obtained product was measured. The serum activity of aspartate aminotransferase (AST) alanine aminotransferase (ALT), lactated dehydrogenase (LDH) and creatine kinase (CK) were measured using Cormay kits (Poland) according to manufacture application on Liasys apparatus (Italy).

The determination of rat's specific fatty acid-binding proteins (FABP, Life Diagnostics, Inc., USA), cardiac troponin I (cTnl, Life Diagnostics, Inc., USA) and B-type natriuretic peptide (BNP-32; Phoenix Pharmaceuticals, Inc., USA) were measured in the plasma according to the manufacture procedures using a spectrophotometric reader PowerWave XT (BioTek, USA) according to manufacture procedures.

\section{Statistical analysis}

The obtained data were analysed using STATISTICA 5.0. (Statsoft Inc., USA). Statistical significance was evaluated by U Mann-Witney test (vs. saline control) and by one-way analysis of variance (Kruskal-Wallis ANOVA). The post-hoc test (Newman-Keuls) was used to verify null hypothesis, according to which the lowered thyroid hormones status influence the evaluated parameters. All data are expressed as mean \pm \pm standard deviation $(M \pm S D)$. The value of $p<0.05$ was considered statistically significant.

\section{RESULTS}

The morphology examination of thyroid gland showed a reduction of follicles colloid in relation to the methimazole concentrations (Fig. 1). It was consistent with biochemical markers tested in the blood, because significantly decreased FT3 and FT4 serum concentrations were found at both tested concentration of methimazole (Table 1). The higher dose of the thyreostatic was responsible for the decrease of FT3 and FT4 below the limit of detection. 

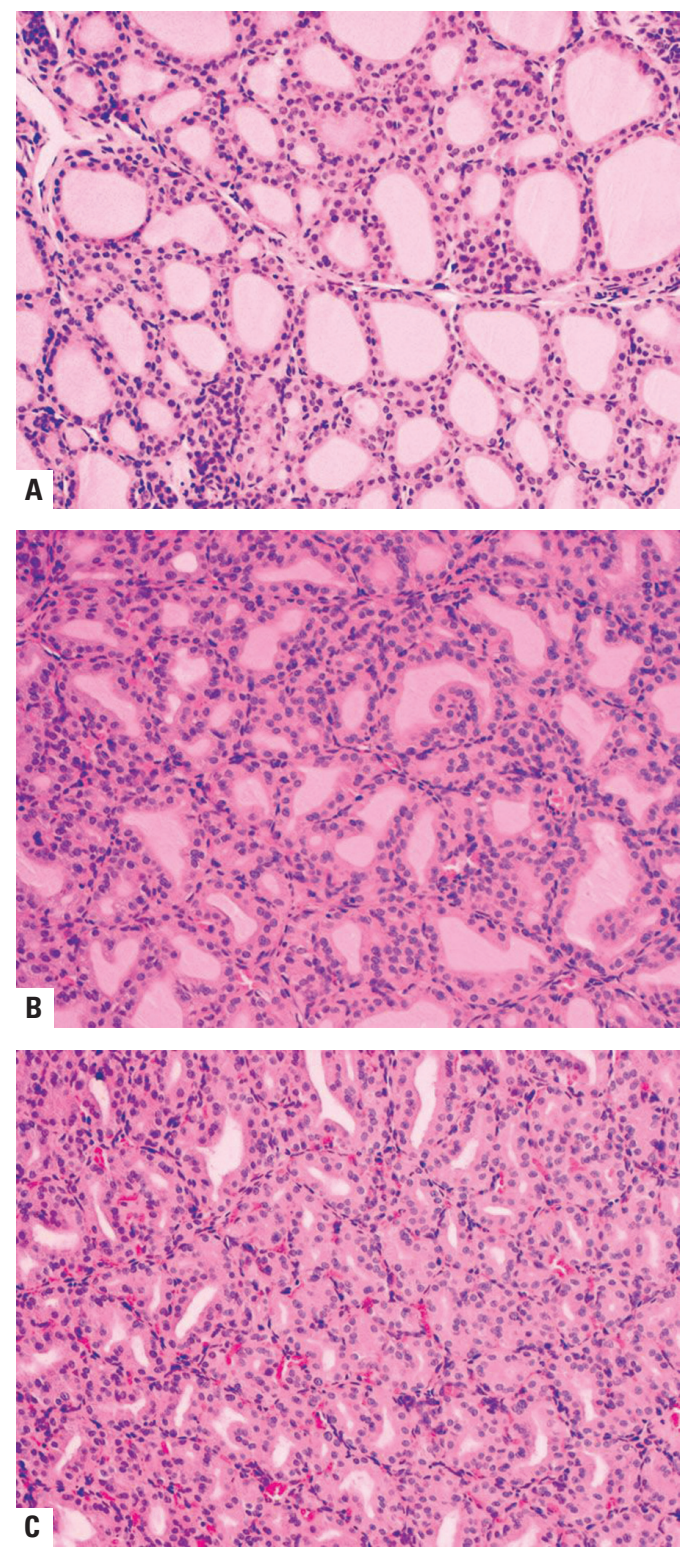

Figure 1. Morphology of thyroid gland $(H+E$, objective $\times 20)$; A. Normal morphology (control); B, C. Colloid reduction in rats receiving methimazole 0.001 and $0.025 \%$, respectively.

Cardiac histological abnormalities, both in cardiomyocytes and interstitial, were observed in most of doxorubicin-exposed rats, but their incidence was not statistically different between groups exposed to the drug alone and co-treated with methimazole (Fig. 2). All morphological changes were time-dependent since slightly higher incidence was found in animals examined at 48 and $96 \mathrm{~h}$, than in shorter periods. Vacuolar and eosinophilic degeneration were the most commonly seen in case of cardiomyocytes. Microvacuolisation was limited to single cells or diffused, whereas macrovacuolisation was found less frequently in single, spread cardiomyocytes. In some cases, wavy direction of myofibrils, as well as cardiomyocytes with strips contractions were also observed.

Among all tested period of time the mean AST levels were higher with dose elevation (Table 2). Similarly, it was found for ALT (Table 3) at 48 and $96 \mathrm{~h}$, for LDH (Table 4) at 4 and $96 \mathrm{~h}$, and for CK (Table 5) at $48 \mathrm{~h}$. In the case of AST, these differences, excluding $2 D O X / 4 \mathrm{~h}$, were statistical significant comparing with the control. A significant elevation in LDH level was observed only for highest dose of doxorubicin in all tested time sequences. A significant increase in CK activity was found after $5 \mathrm{mg} \mathrm{DOX}$ at 4 and $96 \mathrm{~h}$ and after $15 \mathrm{mg} \mathrm{DOX} / \mathrm{kg}$ at $48 \mathrm{~h}$. The comparison of the activity of all tested enzymes in euthyroid and hypothyroid rats treated with lower concentration of methimazole and receiving DOX, revealed a significant changes in $\mathrm{MET}_{0.001 \%}+\mathrm{DOX}$ group at 4 and $96 \mathrm{~h}$, but there were no common trend of these changes across the doxorubicin doses or time observations. Similar comparison for $\mathrm{MET}_{0.025 \%}+\mathrm{DOX}$ group (vs. DOX) indicated that higher concentration of methimazole led to decrease in AST, ALT and LDH activity. However, it was found mainly at $96 \mathrm{~h}$.

Versus control, the FABP (Table 6) and cTnl (Table 7) levels were significantly higher after administration of the highest doxorubicin dose at 4, 48 and $96 \mathrm{~h}$. The middle dose caused marked elevation in cTnl at 48 and $96 \mathrm{~h}$ and FABP at $96 \mathrm{~h}$. Methimazole did not change cTnl level in rats treated with doxorubicin. However, lower concentration of methimazole led to augmentation of increasing level of FABP in group of MET $_{0.001 \%}+15$ DOX at 4 and $48 \mathrm{~h}$.

Table 1. Free tetraiodothyronine (FT3) and triiodothyronine (FT4) level (pmol/L; $M \pm S D$ )

\begin{tabular}{lccc}
\hline & Control & \multicolumn{2}{c}{ Methimazole } \\
\cline { 3 - 4 } & & $\mathbf{0 . 0 0 1 \%}$ & $\mathbf{0 . 0 2 5 \%}$ \\
\hline FT4 & $10.478 \pm 1.118$ & $6.097 \pm 1.547^{*}$ & $<2.60^{* *}$ \\
FT3 & $3.517 \pm 0.495$ & $2.392 \pm 0.569^{*}$ & $<1.67^{* *}$ \\
\hline
\end{tabular}

${ }^{*} p<0.05$ vs. control, **below detection limit 

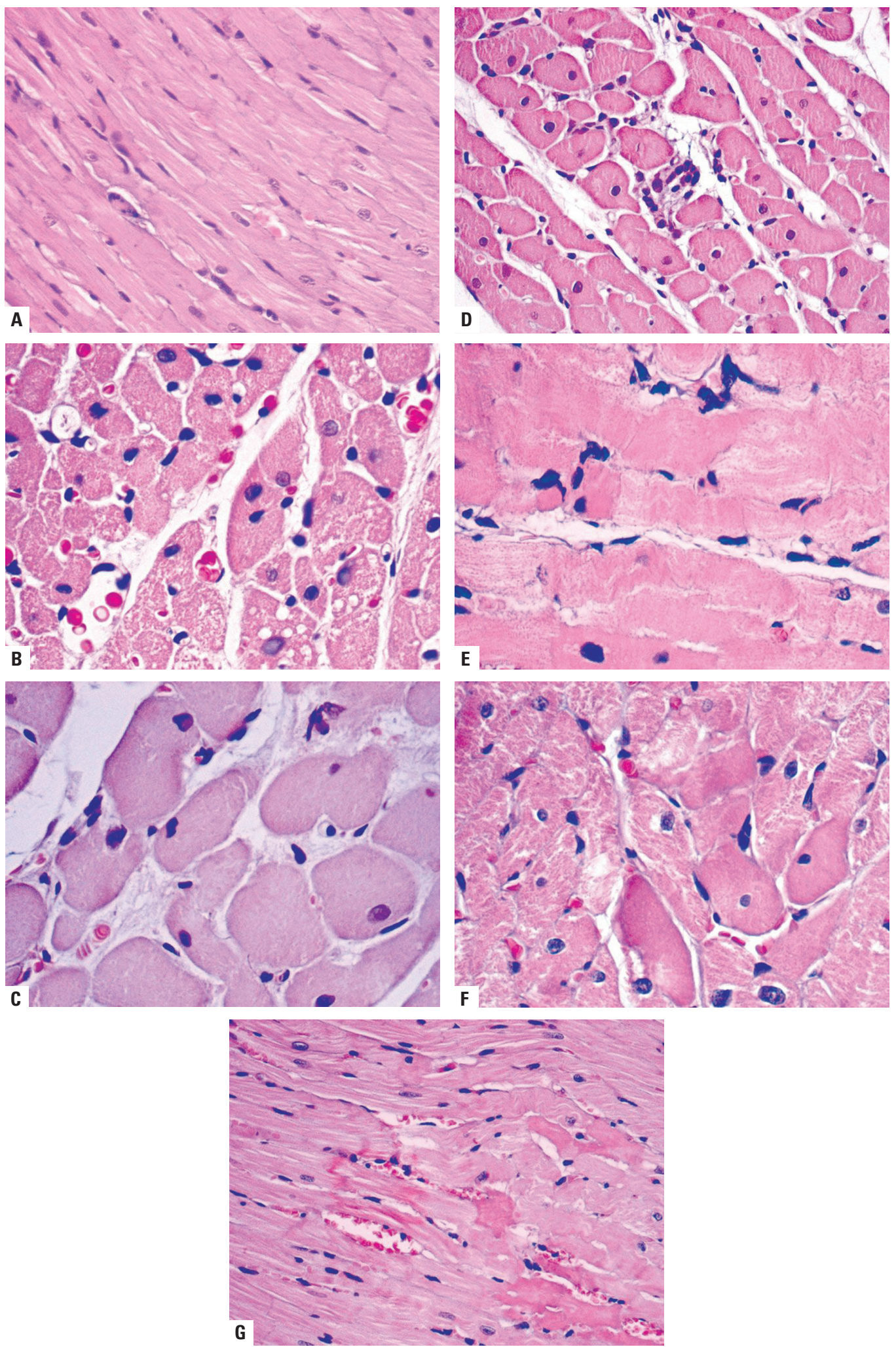

Figure 2. Cardiac histological changes after doxorubicin administration; A. Normal myocardium (control; $\mathrm{H}+\mathrm{E}$; objective $\times 20$ ); B. Microvacuolar degeneration (5 mg DOX/48 h; H+E; objective $\times 40)$; C. Intestinal oedema with cardiomyocytes spreading (5 mg DOX/48 h; H+E; objective $\times 40)$; D. Lesser foci of mononuclear inflammatory cells in myocardium $(15 \mathrm{mg} \mathrm{DOX} / 96 \mathrm{~h} ; \mathrm{H}+\mathrm{E}$; objective $\times 20)$; E. Eosinophilic cardiomyocyte degeneration, wavy direction of myofibrils and macrovacuolar degeneration of the single cardiomyocyte $(15 \mathrm{mg} \mathrm{DOX} / 96 \mathrm{~h}$; $\mathrm{H}+\mathrm{E}$; objective $\times 40$ ); F. Small foci of cardiomyocytes with high eosinophilic degeneration, loss of striation and shrinkage, hiperchromatic nuclei (MET ${ }_{0.01 \%}+15 \mathrm{mg} \mathrm{DOX/96}$ h; H+E; objective $\times 40$ ); G. Irregular direction of eosinophilic cardiomyocytes with loss of striation in area limited by intercalated discs (MET $0.001 \%+15 \mathrm{mg} \mathrm{DOX} / 96 \mathrm{~h} ; \mathrm{H}+\mathrm{E}$; objective $\times 20$ ). 
Table 2. The activity of aspartate aminotransferase (IU/L; $M \pm S D$ )

\begin{tabular}{|c|c|c|c|c|c|}
\hline & \multirow[t]{2}{*}{ DOX [mg/kg] } & \multicolumn{3}{|c|}{ Methimazole } & \multirow{2}{*}{$\begin{array}{c}\text { ANOVA } \\
\mathbf{p}\end{array}$} \\
\hline & & $0.000 \%$ & $0.001 \%$ & $0.025 \%$ & \\
\hline \multirow[t]{3}{*}{$4 \mathrm{~h}$} & 2 & $139.40 \pm 25.37$ & $180.00 \pm 29.74^{*}$ & $151.60 \pm 27.83^{*}$ & 0.1193 \\
\hline & 5 & $177.67 \pm 52.13^{*}$ & $279.50 \pm 79.9^{*}$ & $220.50 \pm 73.44^{*}$ & 0.0853 \\
\hline & 15 & $275.00 \pm 79.14^{*}$ & $490.00 \pm 152.80^{*} \#$ & $236.20 \pm 66.15^{*} \#$ & 0.0120 \\
\hline \multirow[t]{3}{*}{$48 \mathrm{~h}$} & 2 & $217.40 \pm 50.84^{*}$ & $162.20 \pm 36.87^{*}$ & $223.40 \pm 38.71^{*}$ & 0.1075 \\
\hline & 5 & $291.50 \pm 74.85^{*}$ & $260.67 \pm 150.88^{*}$ & $273.66 \pm 93.63^{*}$ & 0.4233 \\
\hline & 15 & $364.00 \pm 178.84^{*}$ & $379.14 \pm 103.47^{*}$ & $510.00 \pm 113.42^{*}$ & 0.1078 \\
\hline \multirow[t]{3}{*}{$96 \mathrm{~h}$} & 2 & $202.00 \pm 28.27^{*}$ & $164.83 \pm 43.27^{*}$ & $149.83 \pm 16.46^{*}$ & 0.0775 \\
\hline & 5 & $248.00 \pm 58.68^{*}$ & $95.60 \pm 8.73^{*} \#$ & $179.40 \pm 48.20^{*} \# \dagger$ & 0.0029 \\
\hline & 15 & $362.60 \pm 29.76^{*}$ & $296.60 \pm 39.71^{*} \#$ & $247.00 \pm 73.28^{*} \#$ & 0.0435 \\
\hline $0.9 \% \mathrm{NaCl}$ & & $113.57 \pm 14.64$ & $161.20 \pm 16.08^{*}$ & $94.60 \pm 20.54$ & \\
\hline
\end{tabular}

DOX — doxorubicin; ${ }^{*} p<0.05$ vs. control $\left(0.9 \%\right.$ NaCl); \#vs. DOX; †vs. MET $_{0.001 \%}+$ DOX

Table 3. The activity of alanine aminotransferase (IU/L; $M \pm S D$ )

\begin{tabular}{lccccc}
\hline & DOX [mg/kg] & \multicolumn{3}{c}{ Methimazole } & ANOVA \\
\cline { 2 - 5 } & & $\mathbf{0 . 0 0 0 \%}$ & $\mathbf{0 . 0 0 1 \%}$ & $\mathbf{0 . 0 2 5 \%}$ & $\mathbf{p}$ \\
\hline $4 \mathrm{~h}$ & 2 & $57.20 \pm 10.33$ & $69.40 \pm 10.38^{*}$ & $62.80 \pm 7.73$ & 0.2051 \\
& 5 & $56.17 \pm 10.99$ & $80.00 \pm 17.89^{*} \#$ & $64.50 \pm 8.78 \dagger$ & 0.0213 \\
& 15 & $91.00 \pm 40.75^{*}$ & $102.14 \pm 16.05^{*}$ & $92.60 \pm 26.82$ & 0.2603 \\
$48 \mathrm{~h}$ & 2 & $63.00 \pm 14.75$ & $77.00 \pm 15.63^{*}$ & $73.00 \pm 16.44$ & 0.3432 \\
& 5 & $85.66 \pm 15.28^{*}$ & $104.00 \pm 84.68^{*}$ & $97.33 \pm 22.03^{*}$ & 0.2912 \\
& 15 & $103.43 \pm 33.60^{*}$ & $97.00 \pm 18.13^{*}$ & $132.80 \pm 18.37^{*}$ & 0.1003 \\
$96 \mathrm{~h}$ & 2 & $61.20 \pm 13.38$ & $55.12 \pm 4.26$ & $46.50 \pm 5.57^{*} \# \dagger$ & 0.0348 \\
& 5 & $118.67 \pm 63.38^{*}$ & $33.00 \pm 8.54^{*} \#$ & $63.80 \pm 22.97 \# \dagger$ & 0.0047 \\
$0.9 \% \mathrm{NaCl}$ & 15 & $132.00 \pm 71.40^{*}$ & $97.00 \pm 54.53$ & $106.20 \pm 19.66^{*}$ & 0.4667 \\
\hline
\end{tabular}

DOX - doxorubicin; * $<0.05$ vs. control $\left(0.9 \%\right.$ NaCl); \#vs. DOX; tvs. $\mathrm{MET}_{0.001 \%}+\mathrm{DOX}$

Table 4. The activity of lactate dehydrogenase (IU/L; $M \pm S D$ )

\begin{tabular}{|c|c|c|c|c|c|}
\hline & \multirow[t]{2}{*}{ DOX [mg/kg] } & \multicolumn{3}{|c|}{ Methimazole } & \multirow{2}{*}{$\begin{array}{c}\text { ANOVA } \\
\mathbf{p}\end{array}$} \\
\hline & & $0.000 \%$ & $0.001 \%$ & $0.025 \%$ & \\
\hline \multirow[t]{3}{*}{$4 \mathrm{~h}$} & 2 & $1462.60 \pm 431.28$ & $1788.40 \pm 303.67$ & $2046.60 \pm 547.04^{*}$ & 0.1791 \\
\hline & 5 & $1824.83 \pm 446.09$ & $1946.33 \pm 662.08$ & $1942.00 \pm 349.28^{*}$ & 0.8420 \\
\hline & 15 & $2374.86 \pm 903.79^{*}$ & $1540.14 \pm 239.46$ & $1962.00 \pm 681.13^{*}$ & 0.1918 \\
\hline \multirow[t]{3}{*}{$48 \mathrm{~h}$} & 2 & $1658.80 \pm 486.46$ & $1025.20 \pm 325.25$ & $1658.60 \pm 506.89$ & 0.0664 \\
\hline & 5 & $1607.50 \pm 573.69$ & $1055.50 \pm 663.24$ & $1339.20 \pm 439.84$ & 0.3426 \\
\hline & 15 & $2359.43 \pm 915.86^{*}$ & $1493.71 \pm 392.02$ & $2187.00 \pm 735.79^{*}$ & 0.0856 \\
\hline \multirow[t]{3}{*}{$96 \mathrm{~h}$} & 2 & $1382.80 \pm 849.06$ & $1667.16 \pm 717.33 \#$ & $1346.16 \pm 299.13 \dagger$ & 0.0322 \\
\hline & 5 & $1657.83 \pm 520.92$ & $738.40 \pm 197.27 \#$ & $1486.60 \pm 388.89 \dagger$ & 0.0108 \\
\hline & 15 & $2893.20 \pm 322.47^{*}$ & $787.20 \pm 124.05 \#$ & $948.40 \pm 166.18 \# \dagger$ & 0.0052 \\
\hline $0.9 \% \mathrm{NaCl}$ & & $1165.71 \pm 549.15$ & $1887.40 \pm 597.68$ & $1664.00 \pm 648.20$ & \\
\hline
\end{tabular}

DOX - doxorubicin; ${ }^{*} \mathrm{p}<0.05$ vs. control $(0.9 \% \mathrm{NaCl})$; \#vs. DOX; †vs. $\mathrm{MET}_{0.001 \%}+\mathrm{DOX}$ 
Table 5. The activity of creatine kinase (IU/L; $M \pm S D$ )

\begin{tabular}{|c|c|c|c|c|c|}
\hline & \multirow[t]{2}{*}{ DOX [mg/kg] } & \multicolumn{3}{|c|}{ Methimazole } & \multirow{2}{*}{$\frac{\text { ANOVA }}{p}$} \\
\hline & & $0.000 \%$ & $0.001 \%$ & $0.025 \%$ & \\
\hline \multirow[t]{3}{*}{$4 \mathrm{~h}$} & 2 & $2841.00 \pm 798.90$ & $2671.20 \pm 572.82$ & $2391.20 \pm 412.12$ & 0.4807 \\
\hline & 5 & $3463.00 \pm 509.23^{*}$ & $2412.83 \pm 547.63 \#$ & $2599.66 \pm 1035.61 \dagger$ & 0.0446 \\
\hline & 15 & $3088.14 \pm 783.29$ & $2998.28 \pm 814.85$ & $2604.50 \pm 1064.25$ & 0.5829 \\
\hline \multirow[t]{3}{*}{$48 \mathrm{~h}$} & 2 & $2870.60 \pm 692.01$ & $2283.80 \pm 405.45$ & $2627.40 \pm 636.40$ & 0.2947 \\
\hline & 5 & $3136.67 \pm 670.23$ & $2317.67 \pm 1096.23$ & $2662.66 \pm 1026.96$ & 0.3429 \\
\hline & 15 & $3710.14 \pm 347.17^{*}$ & $2895.57 \pm 609.39$ & $3198.40 \pm 585.83$ & 0.0511 \\
\hline \multirow[t]{3}{*}{$96 \mathrm{~h}$} & 2 & $3259.80 \pm 570.08$ & $2381.33 \pm 738.80 \#$ & $3643.16 \pm 257.38 * \dagger$ & 0.0110 \\
\hline & 5 & $3550.17 \pm 408.08^{*}$ & $3003.00 \pm 772.30$ & $3064.80 \pm 668.75$ & 0.3668 \\
\hline & 15 & $1834.00 \pm 707.25$ & $3225.00 \pm 411.45 \#$ & $2081.80 \pm 481.31 \dagger$ & 0.0128 \\
\hline $0.9 \% \mathrm{NaCl}$ & & $2453.86 \pm 741.43$ & $3345.80 \pm 435.89$ & $3023.00 \pm 895.33$ & \\
\hline
\end{tabular}

DOX - doxorubicin; ${ }^{*} \mathrm{p}<0.05$ vs. control $(0.9 \% \mathrm{NaCl})$; \#vs. DOX; †vs. $\mathrm{MET}_{0.001 \%}+\mathrm{DOX}$

Table 6. The level of fatty acid binding protein of cardiac origin $(\mu \mathrm{g} / \mathrm{L} ; \mathrm{M} \pm \mathrm{SD})$

\begin{tabular}{lccccc}
\hline & DOX [mg/kg] & \multicolumn{3}{c}{ Methimazole } & ANOVA \\
\cline { 3 - 6 } & & $\mathbf{0 . 0 0 0 \%}$ & $\mathbf{0 . 0 0 1 \%}$ & $\mathbf{0 . 0 2 5 \%}$ & $\mathbf{p}$ \\
\hline $4 \mathrm{~h}$ & 5 & $8.40 \pm 3.09$ & $8.73 \pm 2.88$ & $8.04 \pm 3.14$ & 0.8285 \\
& 15 & $10.53 \pm 3.22^{*}$ & $21.80 \pm 4.73^{*} \#$ & $15.42 \pm 4.55^{*}$ & 0.0296 \\
$48 \mathrm{~h}$ & 5 & $8.85 \pm 2.17$ & $8.82 \pm 2.42$ & $8.50 \pm 4.94$ & 0.8741 \\
& 15 & $11.38 \pm 2.80^{*}$ & $16.07 \pm 3.59^{*} \#$ & $14.00 \pm 3.11^{*}$ & 0.0314 \\
$96 \mathrm{~h}$ & 5 & $10.22 \pm 2.75^{*}$ & $6.45 \pm 2.76$ & $8.82 \pm 1.87^{*}$ & 0.1783 \\
& 15 & $15.07 \pm 4.02^{*}$ & $13.90 \pm 4.06^{*}$ & $13.26 \pm 3.25^{*}$ & 0.7973 \\
$0.9 \% \mathrm{NaCl}$ & & $5.78 \pm 1.79$ & $4.51 \pm 3.41$ & $6.09 \pm 2.80$ & \\
\hline
\end{tabular}

DOX - doxorubicin; * $p<0.05$ vs. control (0.9\% NaCl); \#vs. DOX

Table 7. The level of cardiac troponin I $(\mu \mathrm{g} / \mathrm{L} ; \mathrm{M} \pm \mathrm{SD})$

\begin{tabular}{lccccc}
\hline & DOX $[\mathrm{mg} / \mathrm{kg}]$ & \multicolumn{3}{c}{ Methimazole } & \multicolumn{2}{c}{ ANOVA } \\
\cline { 3 - 6 } & & $\mathbf{0 . 0 0 0 \%}$ & $\mathbf{0 . 0 0 1 \%}$ & $\mathbf{0 . 0 2 5 \%}$ & $\mathbf{p}$ \\
\hline $4 \mathrm{~h}$ & 5 & $0.093 \pm 0.031$ & $0.135 \pm 0.038^{*}$ & $0.117 \pm 0.045$ & 0.2457 \\
& 15 & $0.131 \pm 0.026^{*}$ & $0.228 \pm 0.128^{*}$ & $0.160 \pm 0.057^{*}$ & 0.6183 \\
$48 \mathrm{~h}$ & 5 & $0.168 \pm 0.035^{*}$ & $0.119 \pm 0.025^{*}$ & $0.115 \pm 0.027$ & 0.0581 \\
& 15 & $0.198 \pm 0.119^{*}$ & $0.273 \pm 0.148^{*}$ & $0.236 \pm 0.103^{*}$ & 0.5509 \\
$96 \mathrm{~h}$ & 5 & $0.140 \pm 0.031^{*}$ & $0.114 \pm 0.027$ & $0.083 \pm 0.019$ & 0.0976 \\
& 15 & $0.211 \pm 0.074^{*}$ & $0.317 \pm 0.138^{*}$ & $0.158 \pm 0.042^{*}$ & 0.0976 \\
$0.9 \% \mathrm{NaCl}$ & & $0.069 \pm 0.028$ & $0.058 \pm 0.030$ & $0.053 \pm 0.026$ & \\
\hline
\end{tabular}

DOX - doxorubicin; * $p<0.05$ vs. control $(0.9 \% \mathrm{NaCl})$

Higher dose of doxorubicin leads to increase in BNP (Table 8) level comparing with the control only at $96 \mathrm{~h}$. Referring to particular DOX groups, there were any significant changes in BNP level in rats receiving both doses of methimazole.

\section{DISCUSSION}

The aim of the study was to evaluate the effect of iodothyronine hormones status (FT3 and FT4) on cardiac changes caused by doxorubicin. Dose dependent inhibition of synthesis of iodothyroid hormones 
Table 8. The level of B-type natriuretic peptide $(\mu \mathrm{g} / \mathrm{L} ; \mathrm{M} \pm \mathrm{SD})$

\begin{tabular}{lccccc}
\hline & DOX $[\mathrm{mg} / \mathrm{kg}]$ & \multicolumn{1}{c}{ Methimazole } & \multicolumn{2}{c}{ ANOVA } \\
\cline { 3 - 6 } & & $\mathbf{0 . 0 0 0 \%}$ & $\mathbf{0 . 0 0 1 \%}$ & $\mathbf{0 . 0 2 5 \%}$ & $\mathbf{p}$ \\
\hline $4 \mathrm{~h}$ & 15 & $0.664 \pm 0.282$ & $0.502 \pm 0.188^{*}$ & $0.374 \pm 0.159^{*}$ & 0.3076 \\
$48 \mathrm{~h}$ & 15 & $0.620 \pm 0.282$ & $0.476 \pm 0.128^{*}$ & $0.358 \pm 0.133^{*}$ & 0.1103 \\
$96 \mathrm{~h}$ & 15 & $0.508 \pm 0.188^{*}$ & $0.445 \pm 0.208^{*}$ & $0.302 \pm 0.100^{*}$ & 0.3465 \\
$0.9 \% \mathrm{NaCl}$ & & $0.946 \pm 0.275$ & $0.772 \pm 0.154$ & 0.7380 .304 & \\
\hline
\end{tabular}

DOX — doxorubicin; * $p<0.05$ vs. control $(0.9 \% \mathrm{NaCl})$

resulted from methimazole was confirmed by FT3 and FT4 determination in serum and gland morphology. Taking into account absence of overt clinical symptoms, these results proved that used drinking water concentrations of methimazole were proper for tested model. The selected drug directly inhibits the synthesis of thyroid hormones by interfering with iodine incorporation into tyrosyl residues of thyroglobulin, secondary to interfering with the oxidation of iodide ion and iodotyrosyl groups through inhibition of the peroxidase enzyme. The primary influence on hypothalamus/hypophysis axis was not revealed [1, 27].

In our previous study [12], it was found that hypothyreosis intensifies doxorubicin-related oxidative stress. Because oxidative stress may result in cardiomyocyte apoptosis and/or necrosis, the heart morphology examination and blood markers assessment were conducted.

In most rats from DOX and DOX+MET groups, there were histopathological changes both in cardiomyocytes and interstitium. The frequency of these changes could be shown in following order: microwascular degeneration $>$ macrovascular degeneration $>$ increased eosinophilic cytoplasm > wavy direction of myofibrils. Similar to current study, pathological doxorubicin-related changes were seen in cardiomyocytes and cardiac interstitium. Generally, these changes are typical for doxorubicin. In Arola et al. study [5] rat's cardiomyocytes vacuolisation was observed after doxorubicin administration at dose of $2.5 \mathrm{mg} / \mathrm{kg}$. Furthermore, micro- and macrovacuolisation was found $120 \mathrm{~h}$ after doxorubicin injection at dose of $10 \mathrm{mg} / \mathrm{kg}$ [14]. However, no marked changes even at dose up to $25 \mathrm{mg} / \mathrm{kg}$ were found in mice by Liu et al. [18]. Although hypothyreosis intensified oxidative stress in the heart [12], there were no marked differences in morphological changes among DOX and DOX+MET groups.

A significant elevation in both serum transaminases level in most groups of rats receiving only doxo- rubicin was revealed, but AST was more sensitive marker than ALT. For instance, any changes in ALT level compared with the control was found at the lowest dose of doxorubicin and additionally relative elevations of AST compared with the control were higher than ALT. These results are in agreement with previous studies by Al-Shabanah et al. [3] and Buyukokuroglu et al. [6] who exposed rats to doxorubicin (15 or $20 \mathrm{mg} / \mathrm{kg}$ ) and observed significant increase in AST activity after 24 and 48 h, respectively. Yagmurca et al. [29] revealed that AST activity remains elevated even 10 days after treatment with $20 \mathrm{mg}$ of doxorubicin $/ \mathrm{kg}$. Taking into account that AST is mainly localised in mitochondria [26], observed increase in AST in the blood may suggest serious cells dysfunction. The hypothyreosis influence on changes caused by doxorubicin in both transaminases activity was found very rare. These changes were dependent on the stage of hyperthyreosis and study duration. In most cases hypothyreosis diminished transaminases activity elevated by doxorubicin, thus reducing toxic effect caused by this anticancer drug.

Among doxorubicin alone treated group, the significant increase in LDH levels were revealed in all tested periods of time only at highest dose of this drug. These results are consistent with the previously reported results which had shown an elevation in LDH activity in rats receiving single and repeated doses of doxorubicin $[2,9,10]$. Significant increase in total LDH activity and cardiac isoform activity was also described by Al-Shabanah et al. [3] even at $3 \mathrm{~h}$ after treatment with $15 \mathrm{mg}$ doxorubicin/kg, what implies that source of the enzyme can be cardiomyocytes. Effect of hypothyreosis on LDH changes caused by doxorubicin was seen in 4 cases - only at $96 \mathrm{~h}$. In 3 of these cases LDH activity was lower than in counterpart group of DOX, suggesting, similarly as in transaminase case, that hypothyreosis has diminished harmful effect of doxorubicin. 
An increase in LDH activity in group exposed exclusively to doxorubicin was not associated with CK changes, which abnormalities was notice occasionally in every tested period of time. The significant increase in CK activity was also observed in the studies when doxorubicin was administered as single or repeated doses $[2$, 9]. In the study by Al-Shabanach et al. [3] significant increase in both, total and cardiac isoform of CK was observed in rats $24 \mathrm{~h}$ after doxorubicin administration $(15 \mathrm{mg} / \mathrm{kg})$, suggesting that source of the enzymes might be cardiomyocytes. In the current study, significant changes in blood CK levels between doxorubicin treated euthyroid and hypothyroid rats were found accidentally. The marked decrease in CK activity was noted in $\mathrm{MET}_{0.001 \%}+\mathrm{DOX}_{5 \mathrm{mg}}$ group. Moreover, the changes observed in $96 \mathrm{~h}$ are similar to theses observed for LDH.

Changes in FABP and cTnl levels may be explained by cardiomyocyte damages, less likely by necrosis, since lack of histological features of such complication were revealed. Normal range of FABP in humans and rats is about on the same level [23,24]. The method applied for cTnl monitoring was previously tested by O'Brien et al. [22] who confirmed that it is sensitive and specific method to study cardiac damages in rats.

The elevated blood level of FABP and cTnl was found in prevalent DOX tested group that was associated with cardiac histological changes. However, the effect of methimazole on the doxorubicin cardiac toxicity, stated on the basis of FABP status, was revealed only in rats receiving lower dose of thyreostatic drug at 4 and $48 \mathrm{~h}$, only after maximum dose of doxorubicin used in the study. There were insignificant changes in the level of BNP between euthyroid and hypothyroid rats receiving doxorubicin. Thus, it indicates that hypothyreosis had no effect on heart stretching in rats receiving doxorubicin.

Decreased level of iodothyronine hormones had no impact on cardiac morphological changes and heart stretching in rats receiving doxorubicin. Lower hormonal status had sporadic, diverse effect on blood transaminases, LDH and CK levels, but any relation to time, doxorubicin doses and hypothyroid status was found. Elevated level of FABP in rats with hypothyreosis and receiving doxorubicin, suggests sub-cellular disturbance of cardiomyocytes.

\section{REFERENCES}

1. Abalovich M, Llesuy S, Gutierrez S, Repetto M (2003) Peripheral parameters of oxidative stress in Graves' disease: the effects of methimazole and 131 iodine treatments. Clin Endocrinol, 59: 321-327.
2. Abd El-Gawad HM, El-Sawalhi MM (2004) Nitric oxide and oxidative stress in brain and heart of normal rats treated with doxorubicin: role of aminoguanidine. J Biochem Mol Toxicol, 18: 69-77.

3. Al-Shabanah O (1998) Captopril ameliorates myocardial and hematological toxicities induced by adriamycin. Biochem Mol Biol Int, 45: 419-427.

4. Andican G, Gelişgen R, Civelek S, Seven A, Seymen O, Altuğ T, Yiğit G, Burçak G (2004) Oxidative damage to nuclear DNA in hyperthyroid rat liver: inability of vitamin $C$ to prevent the damage. J Toxicol Environ Health A, 67: 413-420.

5. Arola OJ, Saraste A, Pulkki K, Kallajoki M, Parvinen $M$, Voipio-Pulkki LM (2000) Acute doxorubicin cardiotoxicity involves cardiomyocyte apoptosis. Cancer Res, 60: 1789-1792.

6. Büyükokuroğlu ME, Taysi S, Buyukavci M, Bakan E (2004) Prevention of acute adriamycin cardiotoxicity by dantrolene in rats. Hum Exp Toxicol, 23: 251-256.

7. Chattopadhyay S, Zaidi G, Das K, Chainy GB (2003) Effects of hypothyroidism induced by 6 -n-propylthiouracil and its reversal by T3 on rat heart superoxide dismutase, catalase and lipid peroxidation. Indian J Exp Biol, 41: 846-849.

8. Chen GF, Ronis MJ, Ingelman-Sundberg M, Badger TM (1999) Hormonal regulation of microsomal cytochrome P4502E1 and P450 reductase in rat liver and kidney. Xenobiotica, 29, 437-451.

9. Deepa PR, Varalakshmi P (2003) Protective effect of low molecular weight heparin on oxidative injury and cellular abnormalities in adriamycin-induced cardiac and hepatic toxicity. Chem Biol Interact, 146: 201-210.

10. Dowd NP, Scully M, Adderley SR, Cunningham AJ, Fitzgerald DJ (2001) Inhibition of cyclooxygenase-2 aggravates doxorubicin-mediated cardiac injury in vivo. J Clin Invest, 108: 585-590.

11. Dudka J, Burdan F, Korga A, Dyndor K, Syroka I, Zieba J, Lewkowicz D, Korobowicz-Markiewicz A (2009) The diagnosis of anthracycline-induced cardiac damage and heart failure. Postepy Hig Med Dosw, 63: 225-233.

12. Dudka J, Burdan F, Korga A, Iwan M, Madej-Czerwonka B, Cendrowska-Pinkosz M, Korobowicz-Markiewicz A, Jodlowska-Jedrych B, Matysiak W (2012) Intensification of doxorubicin-related oxidative stress in the heart by hypothyroidism is not related to the expression of cytochrome P450 NADPH-reductase and inducible nitric oxide synthase, as well as activity of xanthine oxidase. Oxid Med Cell Longev, 2012: 139327

13. Dudka J (2006) The role of reactive oxygen and nitrogen species in calcium and iron homeostasis dysregulation in anthracycline cardiotoxicity. Postepy Hig Med Dosw, 60: 241-247.

14. Dziegiel P, Surowiak P, Zabel M (2002) Correlation of histopathological and biochemical appraisal of anthracyclin-induced myocardium damage. Folia Histochem Cytobiol, 40: 127-128.

15. Flores-Morales A, Gullberg H, Fernandez L, Ståhlberg N, Lee NH, Vennström B, Norstedt G (2002) Patterns of liver gene expression governed by TRbeta. Mol Endocrinol, 16: $1257-1268$. 
16. Komosinska-Vassev K, Olczyk K, Kucharz EJ, Marcisz C, Winsz-Szczotka K, Kotulska A (2000) Free radical activity and antioxidant defense mechanisms in patients with hyperthyroidism due to Graves' disease during therapy. Clin Chim Acta, 300: 107-117.

17. Liu D, Waxman DJ (2002) Post-transcriptional regulation of hepatic NADPH-cytochrome P450 reductase by thyroid hormone: independent effects on poly(A) tail length and mRNA stability. Mol Pharmacol, 61: 1089-1096.

18. Liu X, Chen Z, Chua CC, Ma YS, Youngberg GA, Hamdy R, Chua BH (2002) Melatonin as an effective protector against doxorubicin-induced cardiotoxicity. Am J Physiol Heart Circ Physiol, 283: H254-H263.

19. Lombardi A, Beneduce L, Moreno M, Diano S, Colantuoni V, Ursini MV, Lanni A, Goglia F (2000) 3,5-diiodo-L-thyronine regulates glucose-6-phosphate dehydrogenase activity in the rat. Endocrinology, 141: 1729-1734.

20. Mayer L, Romić Z, Skreb F, Bacić-Vrca V, Cepelak I, Zanić-Grubisić T, Kirin M (2004) Antioxidants in patients with hyperthyroidism. Clin Chem Lab Med, 42: 154-158.

21. Minotti G, Recalcati S, Menna P, Salvatorelli E, Corna G, Cairo G (2004) Doxorubicin cardiotoxicity and the control of iron metabolism: quinone-dependent and independent mechanisms. Methods Enzymol, 378: 340-361.

22. O'Brien PJ, Smith DE, Knechtel TJ, Marchak MA, Pruimboom-Brees I, Brees DJ, SprattDP, Archer FJ, Butler P, Potter AN, Provost JP, Richard J, Snyder PA, Reagan WJ (2006) Cardiac troponin I is a sensitive, specific biomarker of cardiac injury in laboratory animals. Lab Anim, 40: 153-171.
23. Ohkaru Y, Asayama K, Ishii H, Nishimura S, Sunahara N, Tanaka T, Kawamura K (1995) Development of a sandwich enzyme-linked immunosorbent assay for the determination of human heart type fatty acid-binding protein in plasma and urine by using two different monoclonal antibodies specific for human heart fatty acid-binding protein. J Immunol Methods, 178: 99-111.

24. Pelsers MM, Chapelle JP, Knapen M, Vermeer C, Muijtjens AM, Hermens WT, Glatz JF (1999) Influence of age and sex and day-to-day and within-day biological variation on plasma concentrations of fatty acid-binding protein and myoglobin in healthy subjects. Clin Chem, 45: 441-443.

25. Ram PA, Waxman DJ (1992) Thyroid hormone stimulation of NADPH P450 reductase expression in liver and extrahepatic tissues. Regulation by multiple mechanisms. J Biol Chem, 267, 3294-3301.

26. Sadowski T (2002) Biochemiczne markery zawału mięśnia sercowego. LabForum, http://www.rochediagnostics.pl/ content/archiwum/labforum/pdf/labforum13.pdf.

27. Szczeklik A (2012) Interna Szczeklika 2012. Podręcznik chorób wewnętrznych (in Polish). Medycyna Praktyczna, Krakow.

28. Waxman DJ, Morrissey JJ, Leblanc GA (1989) Hypophysectomy differentially alters $\mathrm{P}-450$ protein levels and enzyme activities in rat liver: pituitary control of hepatic NADPH cytochrome P-450 reductase. Mol Pharmacol, 35: 519-525.

29. Yagmurca $M$, Fadillioglu E, Erdogan $H$, Ucar M, Sogut $S$, Irmak MK (2003) Erdosteine prevents doxorubicin-induced cardiotoxicity in rats. Pharmacol Res, 48: 377-382. 